MATEC Web of Conferences 47, 01009 (2016)

DOI: $10.1051 /$ matecconf/20164701009

(C) Owned by the authors, published by EDP Sciences, 2016

\title{
Strength of Concrete Containing Rubber Particle as Partial Cement Replacement
}

\author{
Siti Radziah Abdullah ${ }^{1, a}$, Wan Raziman Wan Zainal Abidin ${ }^{1}$ and Shahiron Shahidan ${ }^{1}$ \\ ${ }^{1}$ Faculty of Civil and Environmental Engineering, University Tun Hussein Onn Malaysia, 86400 Parit Raja, Johor, \\ Malaysia
}

\begin{abstract}
Uncontrolled issues of disposal waste tire rubber create huge environmental impact and health hazards. An alternative viable solution to minimize these problems is by utilizing the waste rubber tires in construction materials, which in turn can reduce the use of natural resources and eventually lessen the cost of construction. This paper mainly focuses on the use of waste rubber tires particles in concrete with different set of composition ranging from 3 to $12 \%$ of cement replacement. Concrete cubes size of $150 \mathrm{~mm} \times 150 \mathrm{~mm} \times 150 \mathrm{~mm}$ were prepared for compressive strength test, and concrete cylinders size of $150 \mathrm{~m} \times 300 \mathrm{~mm}$ were prepared for splitting tensile test. The result shows that the compressive and split tensile strength of concrete with rubber as cement replacements is $6-21 \%$ lower than the normal concrete.
\end{abstract}

\section{Introduction}

Concrete is widely used in the construction worldwide and the depletion of natural resources of concrete mix is an issue to worry about. When the demand of these materials increases the cost of construction also rises. By reducing the usage of natural resources in concrete by incorporating with recycle material, it can help to reduce the cost of construction and hence minimize amount of material dump into landfill. Waste materials such as recycled plastic, rice hush ash, waste glass, wood ash are examples of materials that can be utilized in concrete. Of many recycle material that can be used is vehicle tires where the disposal of this material affects the environment [1]. Rubber particles has acceptable workability when it used to replace total aggregate of up to $50 \%$ but the strength is reduced proportionally with substitution of rubber in the mix $[2,3]$. Even though compressive strength is reduced, concrete with rubber particles exhibit ductile and plastic failure rather than brittle failure as found for normal concrete [4]. Other than that, concrete with rubber has good resistance and the shrinkage is almost negligible [5]. In order to achieve the acceptable strength of concrete, rubber content should not be more than $20 \%$ of total aggregate volume [6]. Through microscopic analysis, heterogenous and hydrophoble rubber particle disturb hydration process of cement that lead to loss in compressive strength [7]. A waste from rubber industry called as carbon black also has been used as additive to increase density of concrete that beneficial in strength. Due to its smaller size, it acts as filler that can reduce the permeability of concrete [8]. There are potential for rubber to be used in construction industry, hence, this study explores the potential application of rubber particle as cement replacement in the concrete.

\footnotetext{
${ }^{a}$ Corresponding author : radzia@uthm.edu.my
} 


\section{Experimental Program}

The rubber used in this study was fine rubber from scrap tyres that suitably used as cement replacement in concrete (OPC) due to its fineness as shown in Figure 1. Percentages of rubber particle used to replace the cement by weight were $0 \%, 3 \%, 6 \%, 9 \%$ and $12 \%$ with 0.5 water-cement ratio. The mix design procedure was for Grade 30 . Standard cube specimens of $150 \mathrm{~mm}$ x $150 \mathrm{~mm}$ x $150 \mathrm{~mm}$ were prepared for compressive strength test (BS EN 12390-4) and cylinder specimens with diameter of $150 \mathrm{~mm}$ and $300 \mathrm{~mm}$ height were prepared for splitting tensile test (BS EN 12390-6). Prior to concrete casting, slump of each sets of concrete was measured. Each reported compressive and tensile strength is an average of three testing samples that were tested on 7,28 and 56 days.

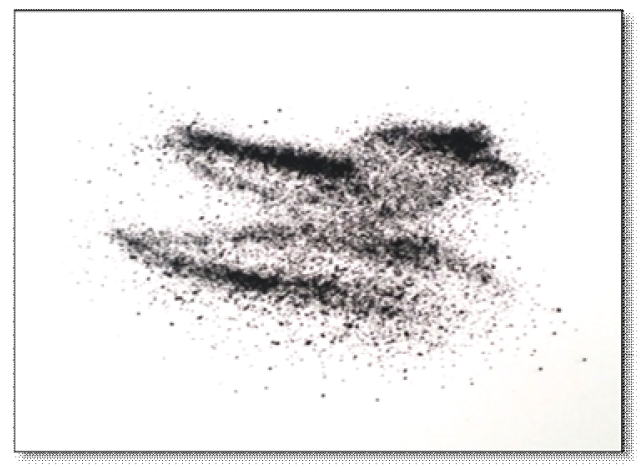

Figure 1. Rubber material.

\section{Results and Discussion}

\subsection{Workability}

The result of the slump test of all types of concrete with rubber particles is shown in Figure 2. As can be seen, increasing the amount of rubber particles as cement replacement in concrete reduce the workability of the mix. In general, the workability of concrete with rubber is lower compared to normal concrete. As for this study constant water-cement ratio was applied in all mix, therefore modification in this ratio can improve the workability without significantly give adverse effect to its mechanical properties.

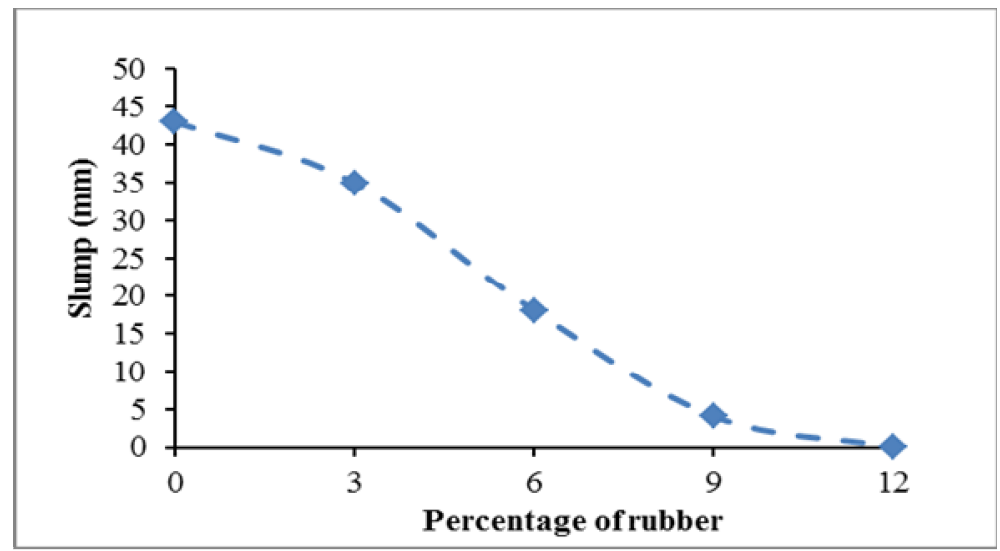

Figure 2. Slump test result. 


\subsection{Compressive strength test}

The compressive strength of concrete cubes containing rubber particle as cement replacements is shown in Figure 3. Concrete with $0 \%$ rubber as cement replacement that act as control specimens has compressive strength of $33 \mathrm{MPa}$ at 28 days. As seen in the figure, replacing $3 \%$ rubber in cement reduces the strength to $27 \mathrm{MPa}$, but the strength increases when more rubber is replaced in the cement. Among all concrete cubes, 9\% rubber shows the best result for 28 days concrete age. The percentage of strength reduction of concrete with rubber is between 6-17\% compared to normal concrete. The compressive strength of these concrete was further assessed for durability. The compressive strength of all the mixtures was increased at 56 days.

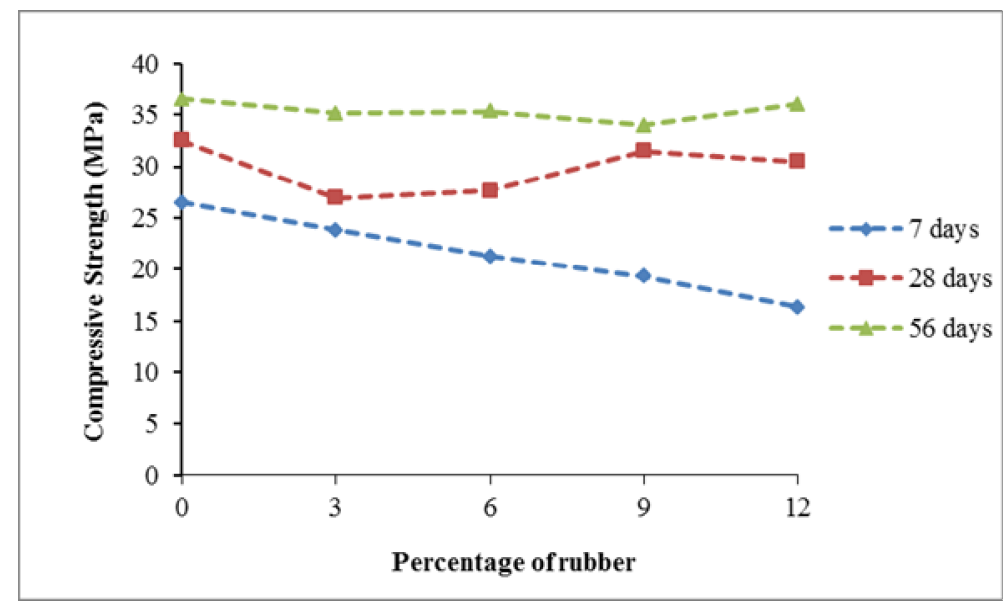

Figure 3. Compressive strength.

\subsection{Splitting tensile strength test}

Figure 4 shows the result of splitting tensile strength of cylinder made of concrete containing rubber as cement replacement. The control specimen with tensile strength of $2.7 \mathrm{MPa}$ at 28 days is compared with other concrete containing rubber particle.

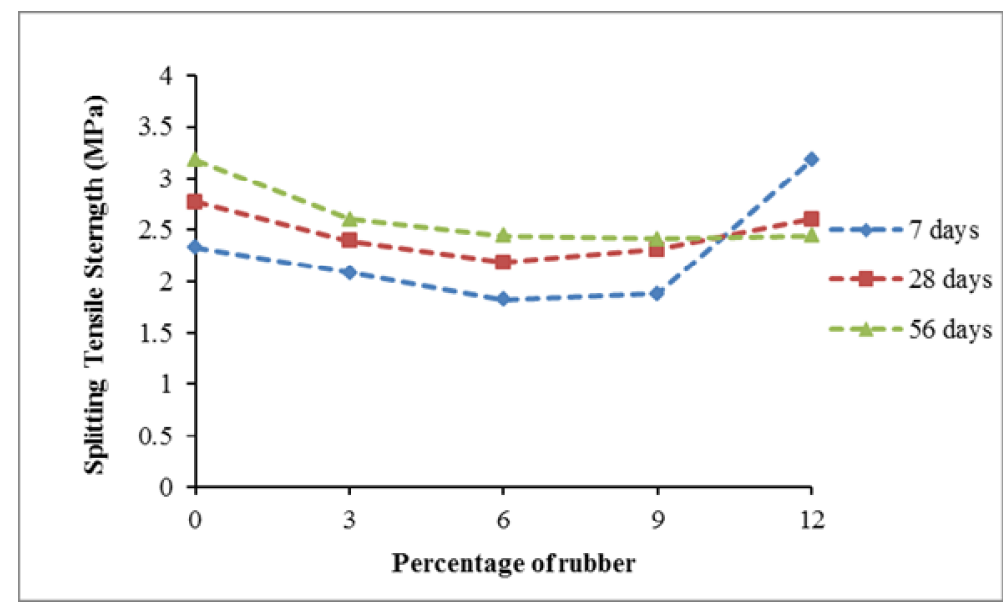

Figure 4. Splitting test strength. 
Reduction in tensile strength is observed for 3\% and $6 \%$ rubber replaced in the cement. After that, tensile strength increases when more percentages of rubber was replaced in the cement. The range of tensile strength differences is between $6 \%$ (concrete with $12 \%$ rubber) to $21 \%$ (concrete with $6 \%$ rubber). An increase in strength was recorded for most concrete when it was tested at 56 days. This findings is consistent with the previous research of rubberize concrete where split tensile strength and other properties are lower than normal concrete [9]. It is suggested that pre-treatment of rubber particles can improve the mechanical properties of concrete as well as its durability $[2,10]$.

\section{Summary}

This paper provides initial study on the effect of rubber as cement replacement in concrete on the compressive and tensile strength of the concrete. In conclusion, the replacement of cement with suitable percentage of rubber can be used in concrete with acceptable compressive and tensile strength as compared to normal concrete. This is because the range of strength reduction is only 6-21 percentage compare with normal concrete. There is room for improvement for rubber as cement replacement such as pre- treatment of the material to increase its strength without adverse effect on workability, durability and cost of the concrete.

\section{References}

[1] V.T. Senthil and R. Thenmozhi, Experimental study on waste tyre rubber replaced concrete - an ecofriendly construction material, Journal of Applied Science Research, 8(6), 2966-2973, (2012).

[2] K.R. Ali, M. Dehestani and P. Rahmatabadi, Mechanical properties of concrete containing a high value of tire-rubber particles, Waste Management, 28(12), 2472-2482, (2008).

[3] K.M. Kotresh and M.G. Belachew, Study on waste tyre rubber as concrete aggregate, International Journal of Scientific Engineering and Technology, 3(4), 433-436, (2014).

[4] A. El-Gammal, A.K. Abdel-Gawad, Y. El-Sherbini and A. Shalaby, Compressive strength of concrete ultilizing waste tire rubber, Journal of Emerging Trends in Engineering and Applied Sciences, 1(1), 96-99, (2010).

[5] Z. Boudaoud and M. Beddar, Effects of recycled tires rubber aggregate on the characteristics of cement concrete, Open Journal of Civil Engineering, 2, 193-197, (2012).

[6] K. K. Zaher and F.M. Boyomy, Rubberized portland cement concrete, Journal of Materials in Civil Engineering, 11(3), 206-213, (1999).

[7] L.H.Chou, C.K. Lu, J.R. Chang and M.T. Lee, Use of waste rubber as concrete additive, Waste Management Resources, 25(1), 68-76, (2007).

[8] G. Chitra, P.V. Selvi and D. Vijayalakshmi, Carbon black as an additive in conventional concrete, International Journal of Emerging Technology and Advanced Engineering, 4(2), 194-201, (2014).

[9] R.H. Ghedan and M.D. Hamza, Effect of rubber treatment on compressive strength and thermal conducticity of modified rubberized concrete, Journal of Engineering and Development, 15(4), 21-29, (2011).

[10]F.P. Torgal, S. Shasavandi and S. Jalali, Tyre rubber wastes based concrete: A review, First International Conference of WASTES: Solutions, Treatments and Opportunities, Portugal, (2011). 